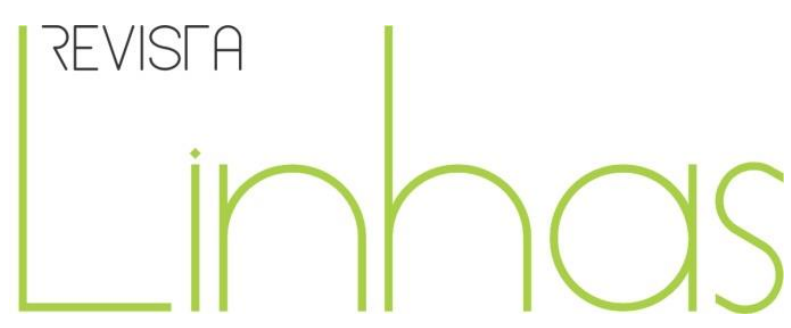

\title{
Corporeidade e educação popular: intervenção teórico-prática em ambiente hospitalar
}

\begin{abstract}
Resumo
A Educação Popular em ambiente hospitalar é o tema tratado neste estudo, que aplica o conceito freiriano do diálogo e o articula com outros dois conceitos, o da corporeidade e o do corpo consciente. Objetiva analisar o processo de compartilhamento de saberes culturais, construção de novos saberes e a busca do ser mais, no pensamento freiriano. Para isso, realiza pesquisa intervenção e, como procedimento metodológico, aplica a técnica da abordagem da ação crítica, que valoriza a relação dialógica e tematiza as ações significativas para os sujeitos envolvidos. Resulta em vivências geradas pela demanda do grupo com novas aprendizagens socioafetivas que promovem conhecimento de si e tomada de consciência das condições de vida de uma mãe em ambiente hospitalar. Conclui que o conhecimento de si pode ocorrer em práticas educativas que fazem dos sujeitos os protagonistas da própria vida, em família e na sociedade.
\end{abstract}

\author{
Marta Genu Soares \\ Universidade do Estado do Pará - \\ UEPA - Belém/PA - Brasil \\ martagenu@gmail.com
}

\section{Ingrid Rodrigues da Rosa Cruz}

Universidade do Estado do Pará UEPA - Belém/PA - Brasil

ingridcruz.r2@outlook.com

Palavras-chave: Educação popular. Corporeidade. Pacientes hospitalizados - Cuidado e tratamento.

\section{Para citar este artigo:}

SOARES, Marta Genu; CRUZ, Ingrid Rodrigues da Rosa. Corporeidade e educação popular: intervenção teórico-prática em ambiente hospitalar. Revista Linhas. Florianópolis, v. 20, n. 44, p. 257-280, set./dez. 2019. 


\title{
Corporation and popular education: theoretical-practical intervention in hospital environment
}

\begin{abstract}
The Popular Educationin in hospital environment is the theme treated in this study that applies the freiriano concept of dialogue and articulates with two other concepts, that of corporeality and that of the conscious body. It aims to analyze the process of sharing cultural knowledge, construction of new knowledge and the search for more being in freiriano thought. It performs intervention research and as a methodological procedure, it applies the technique of critical action approach, which values the dialogic relation, and thematizes the significant actions for the involved subjects. It realizes intervention research and as methodological procedure, it applies the technique of critical action approach, which values the dialogic relation, and it thematizes the significant actions for the involved subjects. It results in experiences generated by the demand of the group with new socio-affective learning that promote knowledge of themselves and awareness of the living conditions of a mother in a hospital environment. It concludes that self-knowledge can occur in educational practices that make subjects the protagonists of life itself, in family and in society.
\end{abstract}

Keywords: Popular Education. Corporeity. Hospitalized patients - Care and treatment. 


\section{Introdução}

Ao falar sobre a saúde pública no contexto amazônico paraense, percebe-se a dificuldade que os moradores de regiões ribeirinhas e interioranas possuem em relação ao acesso aos atendimentos e tratamentos médicos de saúde. Em relação aos familiares dos enfermos, é comum deixarem seus compromissos (trabalhos e estudos) e suas rotinas de vida em busca dos cuidados médicos para seus entes, na "cidade grande". Assim, dotados de cultura e saberes próprios, tal fato nos faz refletir sobre a importância da educação popular freiriana em ambientes públicos de saúde, a qual, a partir do olhar humanizado e dialógico percebe a educação como um processo histórico, vivo, próprio e que também se dá em espaços não escolares.

Diante de tal situação, desde 2014, o Grupo Núcleo de Educação Popular Paulo Freire - NEP da Universidade do Estado do Pará - UEPA, entre outros estudos e projetos, desenvolve práticas lúdicas e pedagógicas com as mulheres/mães de bebês internados na UCI (Unidade de Cuidados Intermediários) e UTI (Unidade de Terapia Intensiva) do hospital Fundação Santa Casa de Misericórdia do Pará - FSCMP, na sala de "Educação e Saúde" que fica no "Banco de Leite" do hospital. O Núcleo de Educação Popular Paulo Freire - NEP, que adota o pressuposto freiriano, busca promover suas práticas pedagógicas pautadas em princípios como diálogo, amorosidade e humanização.

Durante esses anos, desde a sua criação e transformação em Núcleo, o NEP ampliou sua linha de atuação em diferentes espaços, dentre estes, os ambientes hospitalares. O grupo valoriza em suas práticas as diferenças, os saberes e as culturas dos sujeitos e busca, em seus campos de atuação, proporcionar uma educação libertadora, crítica e democrática; sendo assim, o núcleo é “[...] espaço de formação pedagógica, cultural, social, ética, política e, sobretudo, humana" (SILVA, 2009, p. 35).

Ao caracterizarmos o trabalho desenvolvido por dois pesquisadores e oito acadêmicos vinculados ao NEP, neste estudo, no "Banco de Leite" do hospital Fundação Santa Casa de Misericórdia do Pará, vê-se uma educação não formal com jovens e adultos em ambiente hospitalar, que por ser não formal, difere-se de uma classe hospitalar. Logo, diante disso, o NEP busca unir educação popular com ambiente hospitalar, tendo como objetivo pedagógico proporcionar às mulheres/mães de bebês internados na UCl e UTI, as 
quais residem temporariamente no hospital, momentos de compartilhamento de saberes culturais, construção de novos saberes e a busca do ser mais, pensamento freiriano. Assim, podemos caracterizar que a relação da prática do NEP com Freire se dá em três pilares, os quais são: condição filosófica, aporte metodológico e aporte sócio-político.

Quando se fala da condição filosófica em Freire, tem-se na prática educativa a compreensão do inacabamento humano, assim, entende-se que a partir da dialética o sujeito pode ser mais, um ser humanizado, por se encontrar em processo de construção, ou seja, mesmo adulto, este pode e continua aprendendo, pois "Na verdade, o inacabamento do ser ou sua inconclusão é próprio da experiência vital. Onde há vida, há inacabamento" (FREIRE, 1996, p. 22). Dessa maneira, vê-se a educação para além da ideia de idade/série e do "olhar finito" que se possa ter em relação ao saber e ao aprender.

Logo, a partir da dialética em Freire, além de entender que as educandas/mães têm sido sujeitos inacabados, busca-se que percebam seu inacabamento, pois a compreensão acerca do inacabamento humano é condição sine qua non para a construção do saber e expansão de consciência, ao se vivenciar o processo de açãoreflexão, atingindo-se por meio da educação em Freire, a conscientização e a transformação.

Sabe-se que a educação é uma relação humana, ou seja, é uma educação “com”. Diante disto, vê-se no aporte metodológico em Freire o método pedagógico coerente a esse pensamento de educação com educandos e de educação dos educandos. Sendo assim, a partir do diálogo, como princípio freiriano da educação popular, temos um chamamento à problematização, reflexão e ação, pois "não é no silêncio que os homens se fazem, mas na palavra, no trabalho, na ação-reflexão" (FREIRE, 2013, p. 108).

Com o aporte metodológico em Freire, vê-se a valorização do estudo da realidade dos educandos como parte da sistematização dos saberes culturais presentes em espaços não formais, os quais, segundo Albuquerque e Sousa (2016), possuem uma forma singular de inteligibilidade fundamentados na cultura, nas relações com o outro e no cotidiano. Com o estudo da realidade, tem-se os "temas geradores" das práticas educativas, os quais norteiam o processo de codificação, decodificação e expansão de consciência, nas práticas com as educandas/mães, pois, para Freire (2013, p. 136), 
"Investigar o tema gerador é investigar, repitamos, o pensar dos homens referido à realidade, é investigar seu atuar sobre a realidade, que é sua práxis".

Diante de tal processo, vê-se em Freire que a educação popular, além do caráter pedagógico, possui também um caráter político, pois valoriza o engajamento e o enfrentamento social contra a condição de opressão. Com o aporte sócio-político em Freire, entende-se que somos sujeitos históricos e políticos, dessa maneira, construímos nossa história e a sociedade. Com a educação popular em Freire, percebe-se que a transformação do sujeito vai além do surgimento da vontade que este passa a ter em mudar a sociedade, pois alcança uma dimensão de mudança no próprio sujeito em relação a sua posição diante da realidade social em que está inserido. Assim, "A educação como prática da liberdade, ao contrário daquela que é prática da dominação, implica a negação do homem abstrato, isolado, desligado do mundo, assim como também a negação do mundo como uma realidade ausente dos homens" (FREIRE, 2013, p. 98).

A partir do aporte sócio-político da educação popular em Freire, vê-se a educanda/mãe como sujeito que compõe a sociedade, e que como um corposujeito, ou seja, que possui corporeidade, não se encontra à parte do mundo, sendo assim, capaz de compreender a dimensão opressora presente em muitas relações sociais e de se engajar na luta contra as opressões.

$\mathrm{Na}$ pesquisa, surgiram questionamentos pelo grupo do NEP sobre as práticas corporais nas do NEP, ou como as educandas/mães expressam, compartilham e constroem saberes, e ainda sobre a vivência da corporeidade na educação popular em busca da conscientização dos sujeitos sobre seus afetos, sentimentos e ações no cotidiano do hospital e da vida social.

Esses questionamentos conduziram esta investigação que teve por pergunta científica: Como se articulam os conceitos de educação popular e corporeidade nas práticas do NEP com as educandas/mães? Logo, teve-se por objetivos analisar o processo de compartilhamento e construção de saberes, via corporeidade, nas práticas com as educandas/mães e, identificar nas práticas do NEP com as educandas/mães, a vivência da corporeidade na educação popular em busca da conscientização. 


\section{Corporeidade e educação popular em ambiente hospitalar: a busca pela conscientização}

Ao se estudar sobre corporeidade, percebe-se que o termo possui uma dicotomia em relação ao seu conceito, pois epistemologicamente apresenta duas abordagens, uma dualista, na qual há a separação entre o corpo e alma, pensamento cartesiano; e há a concepção holística, que entende o ser humano em sua totalidade. A corporeidade é a expressão do ser, ou seja, é o reflexo de seus pensamentos, suas emoções, suas sensações, seus sentimentos, sua cultura e seus saberes em seu corpo. Assim, deve-se considerar que:

Compreender o corpo vivido na sua múltipla dimensionalidade, integralidade e potencialidade, requer romper as barreiras epistêmicas estabelecidas na sistematização do conhecimento científico, e as técnicas das teorias do conhecimento, para adotar como critério de verdade a prática social, o sujeito histórico e situado que se expressa e transforma a realidade quando produz conhecimento/cultura, portanto, a necessidade do estudo na via de dois conceitos: corporeidade e corporalidade, atrelados ao pensamento fenomenológico e ao pensamento materialista, respectivamente. (GENÚ, 2017b, p. 16)

A corporeidade é um fenômeno que se dá em uma esfera social, pois acontece na relação entre os seres humanos e com o meio em que vivem. Assim, segundo Martins (2015), a corporeidade se dá em diferentes dimensões educativas, dentre elas a sociocultural e a emocional-afetiva, porque a corporeidade é o corpo vivido, o corpo sujeito e o corpo historicamente situado, como diria Paulo Freire (passim). Viver a corporeidade é emancipar-se por meio do processo permanente de conscientização do ser-no-mundo, expressão cara para os princípios freirianos.

Partir dessa compreensão de corporeidade possibilita perceber a relação da mesma com os pressupostos freirianos e a educação popular, ao se fazer uma análise sobre os princípios dessa concepção de educação. Quando se entende que o diálogo faz parte do processo de educação popular, percebe-se que este só se dá no processo de educação pelo fato de o educando poder expor seus saberes, suas culturas e suas emoções ao se considerar a corporeidade do mesmo.

Na dimensão educativa sociocultural da corporeidade, o educando ou educanda expõe seus valores, hábitos e saberes, o que segundo Freire (2013) determina os "temas 
geradores" das práticas pedagógicas fazendo com que essa relação do corpo com o meio seja percebida e vivenciada pelo educando com mais facilidade e consciência, tendo em vista que na perspectiva da corporeidade, admitida no abrigo epistêmico da fenomenologia, carrega de forma imanente a prática social e, portanto, a materialidade vivida. A categoria consciência articula a ação intencional e vivência significativa que concorrem para a formação humana, em que é princípio teleológico ter o corpo e a consciência para o desenvolvimento humano no processo de humanização do sujeito (GENÚ, 2019, p. 19).

Nota-se que essa relação do diálogo freiriano com a dimensão sociocultural da corporeidade é válida para as práticas lúdicas e pedagógicas com os acompanhantes de enfermos que se encontram no hospital, pois a partir do diálogo, nas diferentes formas de expressão do corpo, estes podem indicar a realidade em que vivem. Segundo Genú (2001, p. 117), “corpo e movimento humano são muito mais que ato mecânico de deslocamento no espaço, um está para o outro através da história revelada na análise dos movimentos que o homem realiza através do tempo". Logo, por meio da oralidade, escrita, desenho, pintura, dança e canto, pode-se compreender a realidade dos educandos/acompanhantes, pois o corpo relaciona-se com o outro e se expressa no mundo.

Ao se entender o diálogo, a amorosidade e a humanização como princípios freirianos importantes nas práticas lúdicas e pedagógicas em ambientes hospitalares, o educador se prepara para lidar com as demandas dos educandos/acompanhantes que se encontram no hospital e, dessa maneira, estabelece uma relação de afeto humano ao ajudá-los na busca pela construção de novos saberes, formação humana (ser mais) e engajamento para o enfrentamento social a partir da conscientização.

$\mathrm{Na}$ conscientização por meio de aprendizagens e expressão da corporeidade, o educador proporciona aos educandos possibilidades de ressignificar suas corporeidades passando a ter consciência para seguir o processo de formação humana em meio aos desafios. É necessária a compreensão de que, no processo educativo, o educador lida com pessoas, as quais são corpos-sujeitos e não corpos-objetos. Considera-se o dito: 
Lido com gente e não com coisas. E porque lido com gente, não posso, por mais que inclusive me dê prazer entregar-se à reflexão teórica e crítica em torno da própria prática docente e discente, recusar a minha atenção dedicada e amorosa à problemática mais pessoal deste ou daquele aluno ou aluna (FREIRE, 1996, p. 159)

Dessa forma, percebe-se que o educador precisa considerar a corporeidade de seus educandos, suas emoções, sentimentos, pensamentos, culturas e vivências, pois, as problemáticas da vida têm implicações diretas e indiretas no processo de ensinoaprendizagem, pelo fato de o docente estar lidando com pessoas. Para Genú (2001, p. 122), "a aprendizagem ocorre via a corporeidade em meio à cultura que nos cerca. O que aprendemos é fruto de nossas vivências anteriores e presentes". Logo, é a partir da problematização que os educandos podem chegar à conscientização, ao refletirem criticamente sobre o objeto problema ${ }^{1}$ do processo educativo, o que se percebe na educação popular, pois na busca da formação humana e libertação dos educandos, nessa concepção de educação vê-se além do caráter pedagógico, também o político.

Ao se falar em formação humana, percebe-se que tal discussão pode ser feita a partir de diferentes áreas de conhecimento, pois segundo Genú (2017b, p. 14), "os estudos sobre a formação humana se ampliam e aprofundam tanto pelas áreas do conhecimento com as ciências humanas e sociais, como pelas ciências biológicas e da saúde". Porém, partindo do princípio de educação popular, é impossível falar em formação humana desconsiderando o ser humano como sujeito histórico, pois é a partir da realidade do sujeito que este problematiza, reflete criticamente, conscientiza-se e intervém diante das problemáticas de sua realidade. Para Freire (2013, p. 119), "será a partir da situação presente, existencial, concreta, refletindo o conjunto de aspirações do povo, que poderemos organizar o conteúdo programático da educação ou ação política”.

A partir da discussão sobre formação humana e com a ideia de formação consciente ${ }^{2}$ presente na educação popular, vê-se um viés para a apreciação do conceito de corporeidade, na busca de um corpo consciente, em que "a análise do fenômeno da

\footnotetext{
${ }^{1} \mathrm{O}$ tema ou situação que será discutido, dialogado, analisado e refletido no processo de educação, tanto pelo educador como, principalmente, pelos educandos e educandas.

2 Sentido contrário a uma educação que deposita nas mentes dos educandos conhecimentos préestabelecidos. Tem o sentindo pautado na educação popular freiriana, a qual busca que o educando se conscientize e liberte-se.
} 
corporeidade perpassa pela compreensão de conceitos subjacentes, entre eles: corpo, consciência corporal e omnilateralidade" (GENÚ, 2017b, p. 16). A corporeidade na educação popular compreende o sujeito como um corposujeito, em oposição à visão mecanizada que muitos possuem em relação ao corpo. Assim, na educação popular, quando se busca que o educando se humanize, é preciso que se considere a busca pela formação desse sujeito, a qual Freire (2013) alerta para o sentido de não padronizar o sujeito, mas, para a construção do sujeito consciente, que se inicia por uma "consciência real” e está sempre em busca da "consciência máxima possível”.

\section{A codificação e descodificação na vivência da corporeidade na educação popular}

Em Freire (2013), vê-se que a educação popular além do caráter pedagógico, também apresenta o caráter político em seus fundamentos. Assim, na busca pela formação cidadã, crítica, política do sujeito, podemos dizer que se busca a formação humana, ou seja, de um corpo consciente, isto é, da apropriação da realidade concreta, dos fatos e implicações desses no cotidiano. Logo, ao se discutir sobre essa formação humana, vê-se o ato da codificação e descodificação ${ }^{3}$ na vivência investigativa da prática educativa a partir de uma relação dialógica.

Ao analisarmos os princípios básicos da educação popular, o diálogo é sem dúvida um princípio fundamental para o processo de educação, pois por meio dele é possível manter uma relação mais próxima com os educandos e educandas, podendo conhecer melhor suas histórias de vida, suas culturas, seus saberes, suas experiências e seus projetos de vida para além do espaço educativo, seja escolar ou não. Segundo Freire (2013, p. 109), “o diálogo é este encontro dos homens, mediatizados pelo mundo, para pronunciá-los, não se esgotando, portanto, na relação eu-tu". O diálogo é a essência humana, todos somos seres dialógicos, "por isto, o diálogo é uma exigência existencial” (FREIRE, 2013, p. 109). Ao caracterizarmos a importância do diálogo na prática educativa, observamos que, a partir deste, o processo de codificação pode ocorrer, pois para Freire (2013), codificar é a apreciação da “consciência real”, ou seja, é a problematização da

\footnotetext{
${ }^{3}$ Em Paulo Freire, por toda sua obra, sempre a codificação e descodificação são fases de apropriação da realidade por meio de representação desta, em que o sujeito, ao distanciar-se da própria condição, reflete e analisa sobre os fatos existenciais. Essa fase é o terceiro estágio do processo educativo em Freire.
} 
realidade, do "EU” em busca da "consciência máxima possível”, assim surgindo uma nova percepção e um novo saber, o qual pode ser fruto da sua ressignificação.

Para a codificação, é incontestável que esta parta da realidade dos "sujeitos descodificadores" (educandos), ou seja, dos “temas geradores" das práticas educativas para que possam se reconhecer no fato codificado. Assim, podemos considerar em Freire (2013, p.150), que "uma primeira condição a ser cumprida é que, necessariamente, devem representar situações conhecidas pelos indivíduos cuja temática se busca, o que as faz reconhecíveis por eles, possibilitando, desta forma, que nelas se reconheçam".

Dessa maneira, ao se reconhecerem no fato codificado, os educandos passam a vivenciar o processo de descodificação, assim percebem-se enquanto corpos-sujeitos, refletem sobre sua "consciência real” e no processo de problematização chegam ao novo, percebendo por fim seu antes e depois, pois,

No processo da descodificação os indivíduos, exteriorizando sua temática, explicitam sua "consciência real" da objetividade. Na medida em que, ao fazê-lo, vão percebendo como atuavam ao viverem a situação analisada, chegam ao que chamamos antes de percepção anterior. (FREIRE, 2013, p. 152)

É importante ressaltar que, a partir do processo dialógico, para a descodificação é essencial que o educador como mediador da prática educativa, proporcione tal feito, problematizando o objeto codificado e as próprias respostas que surgem na descodificação, pois dialogar não é apenas ouvir, ou concordar, mas desafiar, problematizar, refletir e se conscientizar.

Compreende-se que a vivência de codificação e descodificação na educação popular traz em seus fundamentos a busca pela libertação do sujeito oprimido, libertação essa diante das "amarras" sociais, políticas, econômicas e educacionais em busca da libertação do ser, nas relações do saber e do poder, sendo assim, a partir da conscientização se atingindo a emancipação do corpo em se expressar na relação com, e para o meio, em diferentes formas de linguagem.

Vale ressaltar que no processo de codificação e descodificação é preciso que se tenha o cuidado para que não ocorra o que Freire (2013) chama de "codificações 
propagandísticas", ou seja, que nesse processo o educando ao invés de problematizar e refletir, acaba descodificando algo previsível ou visto como única opção. Segundo Freire (2013, p. 151), “As codificações não são slogans, são objetos cognoscíveis, desafios sobre os quais deve incidir a reflexão crítica dos sujeitos descodificadores".

Diante o processo de codificação e descodificação, observam-se os movimentos do corpo como expressões da corporeidade facilitando tal processo, em acordo com Genú (2017a, p. 147), “na relação dialógica entre os sujeitos, que pode ser verbal ou não verbal, e gestual, o enunciado é resultante da ação entre os sujeitos e desses com o meio social”. A partir do ato do falar, escrever, desenhar, cantar ou dançar, os saberes, culturas, sentimentos, histórias de vida e desejos são anunciados para o outro e para o próprio sujeito anunciante; logo, via corporeidade, assim com o movimento do corpo, como o ato de desenhar, as subjetividades dos educandos são expressas no processo educativo, e por se vivenciar experiências subjetivas, os resultados de tal processo são diferentes mesmo sendo a partir da mesma ação do corpo, pois:

São diferentes formas de abordar um mesmo movimento, que mudam de acordo com a história de vida, das aprendizagens anteriores, e da maneira subjetiva das vivências. Assim, têm-se respostas ou soluções diferentes para uma mesma manifestação corpórea. (GENÚ, 2017a, p. 150)

Assim, no ato de desenhar ou cantar, por exemplo, o educando comunica-se com o outro e com ele mesmo, tornando o que seria não intencional em intencional, o não relevante em relevante, pois ao ser feita a apreciação do "EU" no objeto problema da prática pedagógica, se problematiza, se constrói um novo conhecimento e/ou o ressignifica, portanto:

Mesmo considerando que é no inconsciente que estão as bases do não intencional e que expressam a organização interna do sujeito na construção do linguajar, da ação comunicativa, da relação eu-mundooutro, as informações e vivências incorporadas são em si as estruturas do intencional. (GENÚ, 2017a, p. 150) 
As diferentes formas de movimentos do corpo são as diferentes formas de linguagem, de comunicar-se, sendo assim, são muito mais do que uma ação mecanizada, são a expressão do ser e a apreciação das vivências anteriores e presentes em busca pelo novo, pois segundo Genú (2017a, p. 150), "a linguagem, como ato social e o discurso corporal devem primar pela intencionalidade operante, no movimento que busca a recriação, o novo, a partir de percepções corpóreas da realidade, das experiências incorporadas".

Portanto, as diferentes formas de comunicação, sejam elas, verbal ou não verbal, são facilitadoras no processo de educação popular no ato de codificação e descodificação, pois o que não poderia ser expresso de forma oral, por exemplo, por meio do desenho, se torna possível. Assim, considerar os movimentos corporais no processo educativo é tornar os educandos protagonistas e não deixa de ser um processo dialógico, amoroso e humanizado.

\section{Aportes para os procedimentos metodológicos}

A pesquisa teve por lócus o hospital Fundação Santa Casa de Misericórdia do Pará - FSCMP, na sala de "Educação em Saúde", localizada no "Banco de Leite” do hospital. Nesse espaço, o grupo de pesquisa Núcleo de Educação Popular Paulo Freire - NEP desenvolve práticas de educação popular com mulheres/mães de bebês internados na UCI e UTI neonatal do hospital, que foram os sujeitos da pesquisa. O estudo teve por modalidade a pesquisa-intervenção, e a preocupação não foi apenas desvendar o objeto de estudo, mas, junto com as pesquisadas, produzir coletivamente novas aprendizagens. Considera-se que

Para tal fim, propomos metodologias coletivas, favorecendo as discussões e a produção cooperativa com a perspectiva de fragilização das hierarquias burocráticas e das divisões em especialidades que fragmentam o cotidiano e isolam os profissionais. A pesquisaintervenção, por sua ação crítica e implicativa, amplia as condições de um trabalho compartilhado. (ROCHA; AGUIAR, 2003, p. 71) 
Dessa maneira, para que fosse desenvolvido um trabalho participativo e dialógico, as atividades da pesquisa foram pautadas nas práticas lúdicas e pedagógicas desenvolvidas pelo grupo Núcleo de Educação Popular Paulo Freire com as mulheres/mães de bebês internados na UCI e UTI do hospital.

O espaço hospitalar lócus da pesquisa é um espaço bastante instável, pelo fato das educandas/mães "residirem" temporariamente no lugar, seja há dois meses, um ano ou, para algumas, de ser o primeiro dia dessa difícil jornada. Logo, nas atividades do grupo (NEP e pesquisadoras), nem sempre o conjunto de educandas era o mesmo, pois a qualquer momento elas poderiam sair do hospital, seja pela melhora, pela transferência do bebê para outro hospital ou, em casos mais sérios, com o óbito do bebê. Assim, no decorrer da pesquisa tivemos um total de trinta educandas/mães participando das práticas, porém esse número não corresponde a todos os dias de práticas, pois houve dias em que compareciam apenas cinco educandas, por exemplo.

Em alguns aspectos, o lócus da pesquisa também pode ser considerado como heterogêneo, no que diz respeito às idades das educandas/mães, que variam dos 13 aos 30 anos de idade, e também quanto aos seus saberes culturais e escolares. $O$ humores das educandas/mães, também eram distintos, pois estavam ligados ao quadro de saúde de seus bebês. Quanto à escolaridade, mais uma vez, há diferenças, pois algumas não terminaram o ensino fundamental $I$, outras ainda estão cursando o ensino médio e pouquíssimas estão no ensino superior.

No decorrer da pesquisa, foi realizada a observação participante em cada dia de atividade e, para as entrevistas, foram escolhidas três educandas/mães, que participaram frequentemente das práticas com o grupo de pesquisadores do NEP, constituído por pedagogas, psicólogas, filósofos e estudantes desses cursos com iniciação à pesquisa.

O NEP é um grupo que tem suas atividades conduzidas por educadoras populares, três estudantes do curso de Pedagogia e uma pedagoga mestranda em Educação. Nessa intervenção, foi desenvolvido pelo grupo (NEP e pesquisadoras), um projeto de ação chamando: "Cuidados com Bebê, Cuidados Comigo", no qual se adotou a Abordagem da Ação Crítica - AAC. A duração do projeto foi de abril a novembro de 2017. 
Para a pesquisa-intervenção foi adotada a teoria Abordagem da Ação Crítica AAC, como técnica de pesquisa e que se constitui de três procedimentos: tematização, apropriação e sistematização (GENÚ SOARES, 2018). Essa abordagem tem como suporte teórico a Teoria Curricular Crítica e a Concepção de Educação Libertadora e, como conceitos fundantes, o diálogo, a consciência e o movimento intencional. Na medida em que sua aplicação é também procedimento didático, ela se apresenta na dimensão investigativa, porque é método de conhecimento e apropriação da realidade na perspectiva de Paulo Freire.

Na tematização, o tema de aula é apresentado e apreciado pelo grupo, momento em que o professor faz o estudo da realidade (ER em Paulo Freire) do grupo e todos participam expressando o conhecimento e experiência sobre o tema de aula. Nesse momento, a abordagem sobre o tema é oral, corporal, escrita ou desenhada, o que foi realizado com as educandas/mães; assim, a partir do estudo de suas realidades, surgiram os “temas geradores” que norteavam todas as práticas pedagógicas.

$\mathrm{Na}$ apropriação, a pesquisa-intervenção se desenvolve em três movimentos pensar e fazer; fazer com o outro; o jeito de ser e de fazer. O objeto de estudo é vivenciado por cada um a partir da experiência individual e pode ser verbalizado para trocas de conhecimento. Na sequência, a atividade pode ser feita em duplas ou trios, de acordo com a opção metodológica do pesquisador, quando o fazer juntos favorece a variação na vivência.

Por fim, o grupo aprecia diferentes formas de fazer ou pensar o tema proposto, no grupo e em outras situações e contextos. Dessa maneira, as educandas/mães puderam em duplas, trios ou em grupo, apropriar-se do objeto problema da prática educativa a partir da problematização e codificá-lo em um processo dialógico.

Na sistematização do tema para expressão da vivência, o pesquisador propõe uma síntese mimética (mimeses termo crítico e filosófico do grego. Interpretação assemelhada à imitação), roda de conversa ou atividade proposta pelo grupo que culmine com a vivência e possibilite a reflexão com elaboração do pensamento crítico sobre a situação temática vivida. Assim, a partir da apreciação da sua realidade, de seus saberes ao problematizar a temática dialogada, as educandas/mães puderam refletir sobre tal 
tema, suas relações com sobre ele e sobre a relação com as outras educandas, assim, ressignificando suas corporeidades por meio da vivência de codificação e descodificação.

Os procedimentos metodológicos das práticas desenvolvidas com as educandas/mães foram divididos em momentos importantes, os quais foram: o momento de dinâmicas, em que as educandas/mães expressaram por meio de desenho, oralidade, escrita e expressão corporal seus sentimentos, pensamentos e saberes, surgindo nesse momento os "temas geradores" dos encontros. Em um segundo momento, foram feitas atividades voltadas à temática que surgiu para o determinado encontro, e o terceiro momento foi destinado para que as educandas/mães refletissem sobre as práticas desenvolvidas no encontro, e como elas se enxergam antes e depois desse encontro.

As práticas desenvolvidas com as educandas/mães ocorreram em quatro momentos, os quais eram denominados pelo grupo do NEP como convite, dinâmicas de estudo, atividades temáticas e reflexão. Assim, dentro da AAC, os momentos do convite e dinâmicas de estudo, correspondiam à tematização. O momento de atividades temáticas correspondia à apropriação e o momento de reflexão correspondia à sistematização, que se deu no decorrer do processo, tendo também um momento especial no final do projeto de ação.

Convite: momento em que o grupo (NEP e pesquisadoras) tinha acesso às $\mathrm{UCl}$ e UTI para convidar as educandas/mães a participarem das práticas na sala de "Educação e Saúde". De todos os procedimentos, esse era o mais desafiador, pois o convite precisava ser atraente o suficiente para que as mães deixassem de estar com seus bebês por um tempo, para participarem das atividades do grupo. Ao conversarmos com as mães na ocasião, já era possível fazer um estudo da realidade delas no hospital para a problematização de possíveis temáticas a serem discutidas.

Dinâmicas de estudo: nesse momento, eram feitas dinâmicas de acolhimento e apresentação do grupo e das educandas/mães, as quais se expressavam por meio de desenho, oralidade e escrita. A expressão do corpo, seus sentimentos, pensamentos e saberes, resultou nos "temas geradores". Assim, com os momentos do convite e dinâmicas de estudo, foi possível definir o tema principal do projeto de ação, e no decorrer das práticas, os subtemas do projeto. 
Atividades temáticas: eram feitas atividades voltadas aos "temas geradores", ocorrendo a apropriação dos subtemas. A partir do diálogo e das atividades, as educandas/mães, no coletivo e no individual, codificavam e descodificavam o objeto problema, o qual era o "tema gerador” da prática educativa.

Reflexão: momento em que as educandas/mães refletiam sobre as práticas desenvolvidas no encontro. A partir de roda de conversa ou produção de textos com um olhar crítico, elas refletiam como se enxergavam antes e depois das práticas com o grupo.

Norteadas pelos princípios freirianos (diálogo, amorosidade e humanização), buscou-se sempre proporcionar o diálogo com as educandas/mães pois, segundo Freire (2013, p. 108), “a existência, porque humana, não pode ser muda, silenciosa, nem tampouco pode nutrir-se de falsas palavras, mas de palavras verdadeiras, com que os homens transformam o mundo". A todo momento as educandas foram protagonistas, tendo suas vozes ouvidas e suas corporeidades compreendidas.

Para a coleta de dados foi utilizada a observação participante, nas práticas realizadas pelo grupo, e a entrevista semiestruturada. A dinâmica da coleta de dados se deu da seguinte maneira: nos momentos de atividades (convites, dinâmicas de estudo, atividades temáticas e reflexão), as falas das educandas eram registradas em um caderno apropriado para isso, e também as atitudes, comportamentos e as expressões das educandas/mães. No final, eram feitos relatórios de cada dia de intervenção do grupo. Segundo Gil (2008), esses procedimentos possibilitam que a pesquisa não perca seu caráter humano, o que é válido para este estudo por lidar com a valorização das pessoas.

Para além da observação participante, também foram realizadas entrevistas semiestruturadas com três educandas/mães, as quais participaram de todas as práticas do projeto de ação no decorrer da pesquisa.

Partindo do princípio de ética na pesquisa, os nomes das educandas/mães, foram mantidos em sigilo para preservar a imagem e integridade destas e para que se sentissem mais confiantes e a pesquisa fluísse com maior precisão. Para isso, pensou-se tratá-las usando siglas, mantendo todas no anonimato e preservando o direito à segurança e dignidade das mesmas. 
As educandas entrevistadas foram denominadas na análise de dados pelas siglas “RT", "LT" e "SM". As educandas mencionadas a partir da observação foram denominadas pelas siglas “IV”, “RS”, “JL”, “AM”, “PT”, “LT”, “SM”, “DS” e “CL”.

Esta pesquisa teve duração de um ano, sendo assim, as entrevistas foram realizadas em um mês (dezembro de 2017) após a parte prática da pesquisa; já a observação participante, ocorreu desde o início da pesquisa, que foi no mês de abril até novembro de 2017, o que correspondeu à duração do projeto de ação desenvolvido com as educandas/mães.

Os itens que nortearam a coleta de dados na observação participante e as perguntas das entrevistas foram divididos em três categorias: educandas/mães e prépráticas LPs, educandas/mães e vivências nas práticas LPs e educandas/mães e percepções pós-práticas LPs. Os itens norteadores da observação e as perguntas das entrevistas abordavam questões sobre os saberes que as educandas possuíam e que construíram a partir das vivências na sala de "Educação e Saúde" e, também, sobre os sentimentos e expressões (corporeidade) das educandas (antes, durante e pós-práticas). Assim, para a análise dos dados de acordo com as categorias de análises, foram feitas as transcrições e análise das entrevistas, análise dos registros da observação e as discussões a partir do aporte teórico deste estudo, o que ocorreu nos meses de janeiro a abril de 2018.

As vivências e elaborações do grupo de educandas foram coletadas e analisadas a partir da criação de palavras geradoras que se organizaram pela recorrência durante a aplicação da AAC, e essas recorrências resultaram em categorias para interpretação à luz dos conceitos e princípios que sustentam o estudo. Dessa forma, os procedimentos metodológicos da pesquisa estiveram pautados nos princípios freirianos, assim como as práticas lúdicas e pedagógicas desenvolvidas pelo grupo Núcleo de Educação Popular Paulo Freire - NEP.

Considerando-se a ética na pesquisa, e em acordo com a submissão ao Comitê de Ética, foi entregue às educandas/mães, de forma individual, o termo de consentimento livre e esclarecido (TCLE), para a realização da entrevista e todos os demais procedimentos da pesquisa e o Termo de Gravação de Voz, para que fosse autorizado o 
uso de respostas, falas e áudios neste trabalho, pois se considera o artigo $2^{\circ}$ da Resolução 510/2016 - CNS:

Para os fins desta Resolução, adotam-se os seguintes termos e definições: I - assentimento livre e esclarecido: anuência do participante da pesquisa - criança, adolescente ou indivíduos impedidos de forma temporária ou não de consentir, na medida de sua compreensão e respeitadas suas singularidades, após esclarecimento sobre a natureza da pesquisa, justificativa, objetivos, métodos, potenciais benefícios e riscos. A obtenção do assentimento não elimina a necessidade do consentimento do responsável. (BRASIL, 2016)

Também, para a realização desta pesquisa, passou-se pelo Comitê de Ética da Universidade do Estado do Pará UEPA/CCBS e da Fundação Santa Casa de Misericórdia do Pará, pois "a pesquisa em ciências humanas e sociais exige respeito e garantia do pleno exercício dos direitos dos participantes, devendo ser concebida, avaliada e realizada de modo a prever e evitar possíveis danos aos participantes" (BRASIL, 2016, p. 01).

\section{As práticas de educação popular e a vivência da corporeidade em ambiente hospitalar}

Diante do grupo de educandas/mães que participaram das práticas pedagógicas do NEP, é perceptível que a maioria vem de regiões interioranas e ribeirinhas do estado do Pará, as quais deixaram suas rotinhas de vida, suas famílias, seus trabalhos e estudos em busca dos atendimentos e tratamentos de saúde para seus bebês no hospital FSCMP. O período de "moradia" dessas educandas/mães na FSCMP varia de dias até meses, sendo uma batalha a ser enfrentada por essas mulheres, que a cada dia, a cada experiência, a cada surpresa, seja triste ou alegre constroem aprendizagens, pois vivenciam o processo natural do ser humano, o de ser um sujeito inacabado, sendo assim, um eterno aprendiz (FREIRE, 2013).

Partindo da condição filosófica em Freire, vê-se as educandas/mães como mulheres que possuem saberes próprios e que constroem novos saberes característicos deste espaço, os quais são fundamentados na cultura local, na relação com o outro e com o meio. 
Nos momentos de dinâmicas de estudo, foram identificadas nas falas das educandas, a necessidade de problematizar duas temáticas: cuidados com o bebê, pois muitas mães eram adolescentes, outras era o primeiro filho ou o primeiro filho prematuro (o que demanda cuidados específicos), e também o cuidado com as próprias mulheres/mães, seja com o corpo, como com o emocional e cognitivo.

A partir da observação participante, muitos dados foram obtidos não só para as intervenções, como para a própria pesquisa. Com a observação realizada no momento de tematização (convite e dinâmicas de estudo), foi possível definir os subtemas do projeto de ação: "Cuidados com o bebê e comigo/Alimentação", "Cuidados com o bebê e comigo/Higienização", "Cuidados com o bebê e comigo/Quem sou no hospital? " E "Cuidados com o bebê e comigo/Quem sou na sociedade?".

Dessa maneira, no momento de apropriação (atividades temáticas) foi possível observar as problematizações feitas pelas educandas/mães. Na apropriação no subtema “Cuidados com o bebê e comigo/Alimentação", elas problematizaram seus saberes culinários passados pela geração familiar, o que resultou na produção do "Livro de Receitas Populares". As receitas foram sobre remédios caseiros e comidas populares para mulheres gestantes, ou que acabaram de ter filhos, e para os bebês.

A experiência propiciou compartilhamento de saberes e construção de aprendizagens. O interessante foi perceber que algumas das receitas eram as mesmas, mas com alguns ingredientes e o modo de preparar diferentes e, ao problematizarem isso, chegaram à conclusão quanto à diversidade cultural e recriação, como é perceptível com o registro das falas sobre o conhecimento de receitas caseiras para doenças domésticas, como chás com folhas regionais, aprendidas com antepassados e identificadas em diferenciações de preparação e consumo.

Observa-se que as educandas codificaram suas realidades ao construir o livro e puderam descodificá-las, se reconhecendo neste, e refletindo sobre ele no momento de produção, não ocorrendo a “codificação propagandística” e sim as suas descodificações, pois foram suas análises, sobre o objeto problema da prática, pois segundo Freire (2013, p. 151) "na medida em que representam situações existenciais, as codificações devem ser simples na sua complexidade e oferecer possibilidades plurais de análises na sua descodificação, o que evita o dirigismo massificador da codificação propagandística”. 
Um fato que chamou bastante atenção foi a problematização de uma educanda/mãe quando, ao explicar sobre a receita de sua avó (sorvete de açaí com limão), relacionou-a com a medicação que estava fazendo no hospital para combater a anemia. Segundo a educanda, tanto a sua receita popular, quanto a medicação do hospital, possuem o mesmo efeito que é a reposição de ferro no sangue.

Percebemos no ato codificado e descodificado, via corporeidade, a apropriação do aporte sócio-político em Freire da educação popular, pois a educanda refletiu criticamente que não existe um único saber, mas saberes que coexistem. Assim, segundo Albuquerque e Silva (2016, p. 232) “[...] para além do conhecimento científico existem saberes que se inscrevem em outros critérios de inteligibilidade do real, não necessariamente estabelecidos pela ciência moderna, tal como a aludida 'sabedoria que grita nos mercados"”.

Com a vivência da corporeidade na educação popular, vê-se um processo de busca pela conscientização, pois como seres inacabados, busca-se o ser mais, assim, as educandas/mães vivenciam o processo de humanização, ou seja, a busca da expansão de consciência, como corpos conscientes que diante das formas de opressão presentes na sociedade, podem se engajar politicamente, resistir e enfrentar socialmente tais opressões, o que também é viável para o período de “moradia” dessas mulheres no hospital.

Ante a vivência da corporeidade na educação popular, percebe-se que as educandas, nessa busca do ser mais, se percebem como sujeitos conscientes e capazes de resistir e lutar contra certas limitações que sofrem ao estarem no hospital. Desse modo, identificaram-se momentos de construção de novos saberes, os quais segundo Albuquerque e Silva (2016) não se entende, necessariamente, de acordo com um pensamento de educação formal, pois "como saberes produzidos no cotidiano social, os saberes culturais não estão, necessariamente, submetidos a processos de escolarização" (ALBUQUERQUE; SILVA, 2016, p. 239).

Dentre as limitações do ambiente próprio do hospital, as educandas/mães trocam saberes e cuidados necessários para o convívio diário e trocam experiências que as ajudam a manter a segurança para a saúde do coletivo e o devido tratamento aos seus bebes. 
Ao serem questionadas quanto à "proteção de celular", muitas falas foram significativas como se identifica nos relatos a seguir: "É interessante porque não dá para ficar sem o celular, porque preciso falar com meu marido, minha família (EDUCANDA “L.T”, coleta de dados, informação oral 2017), ou ainda, "O celular é importante porque a gente tem um grupo no WhatsApp, aí a gente marca para ir tomar banho, comer, assistir TV e conversar, porque aqui a gente cria uma família" (EDUCANDA “S.M", coleta de dados, informação oral, 2017).

Segundo Albuquerque e Silva (2016), os saberes culturais são saberes vivos, os quais se revelam na vivência, na relação com o outro e que possuem uma sistematização, organização, complexidade e regra própria, que diferem do saber que vem dos livros escolares.

Outro momento importante para análise em relação às práticas do NEP, está voltado à amamentação. Em uma oficina realizada pelo grupo, sobre cuidados com o corpo da mulher e com o bebê, foi vivenciado o momento de amamentação, no qual muitos saberes foram compartilhados e outros construídos. Segundo as educandas, muitas não conseguem amamentar seus bebês, pois estes não "pegam o peito", o que contribui para o que elas chamam de "leite pedrado". Para solucionar o problema, as nutricionistas do hospital ensinam uma massagem para evitar que o leite fique “pedrado", porém as mães relataram que tal massagem é bastante dolorida, o que resultou em um momento interessante, no qual uma educanda citou que aprendeu a fazer uma massagem menos dolorida. Ao compartilhar tal saber com as demais educandas se vivenciou um momento de oficina sobre amamentação e reflexão a respeito do cuidado com o corpo da mulher e sobre a violência médica, à qual são submetidas muitas vezes.

Ao se articular, nas práticas do NEP, os conceitos de educação popular e corporeidade, as educandas/mães compartilham e constroem saberes a partir de suas corporeidades, expressas nas trocas e percepções apreendidas com o outro e, dessa forma, alcançamos o primeiro objetivo na intervenção investigada com o processo de compartilhamento e construção de saberes, via corporeidade, nas práticas com as educandas/mães em que os "temas geradores" são codificados, descodificados.

Essa descodificação respondeu ao segundo objetivo da pesquisa intervenção quando se identificou nas práticas do NEP com as educandas/mães, a vivência da 
corporeidade na educação popular voltada para a conscientização, como resultado. Aqui, postula-se o pressuposto do corposujeito tanto na acepção da corporeidade, como em Freire, já que esses sujeitos tematizaram suas histórias de vida, sentimentos e emoções em práticas corpóreas que culminaram em leitura da prática social e conscientização da condição de vida no estágio contextual.

\section{Considerações finais}

Nesta pesquisa foi possível perceber, a partir da compreensão do inacabamento humano, que o processo educativo se dá independentemente da idade ou de um padrão de educação. Assim, com uma prática dialógica, amorosa e humanizada, as educandas/mães vivenciam a busca do ser mais, de serem seres críticos, políticos e humanizados diante das situações de enfrentamento social.

Ao partir do objetivo de identificar nas práticas do NEP com as educandas/mães, a vivência da corporeidade na educação popular em busca da conscientização, notou-se que via corporeidade, as educandas/mães puderam se (re)conhecer, problematizar, dialogar e refletir de forma consciente a respeito de suas realidades, expandindo suas consciências. Nas práticas do NEP em ambiente hospitalar com as mães de bebês internados em UCI e UTI da FSCMP, notou-se que a partir do (re)conhecimento de si, as educandas/mães problematizaram, refletiram e se conscientizaram de suas realidades.

Vê-se que a educação popular não é uma prática assistencialista, mas, uma prática pedagógica e política, que tem o educando como sujeito histórico, sendo corpos-sujeitos, corpos conscientes e que via corporeidade podem ressignificar a vida em diferentes situações existenciais, visto que ao vivenciarem o processo de codificação e descodificação dos momentos vividos e que levam ao conhecimento de si e à aprendizagem, tornam-se protagonistas da própria vida e com possibilidades de compreender situações-problemas e transformá-los em fatos passíveis de resolução. A consciência do ser sujeito e a vivência da corporeidade permitem o vir a ser um sujeito humanizado, um ser consciente das condições sociais.

Esta pesquisa constatou que é possível articular os conceitos de educação popular e corporeidade em vivências práticas, como ocorreu nas intervenções do grupo de 
pesquisadoras com as educandas/mães na sala de "Educação e Saúde" do hospital a partir da valorização do diálogo crítico, da escuta sensível, da percepção do outro e da percepção de si.

\section{Referências}

ALBUQUERQUE, Maria. Betânia. B.; SOUSA, M. B. Saberes Culturais. In: ALBUQUERQUE, Gerson; PACHECO, Agenor (org.). Uwakuru: dicionário analítico. Rio Branco: Nepan, 2016.

BRASIL. Ministério da Saúde. Conselho Nacional de Saúde. Resolução 510/2016. Brasília, DF: Ministério da Saúde, 2016b. Disponível em:

<http://conselho.saude.gov.br/resolucoes/2016/reso510.pd>. Acesso em: 19 ago. 2017.

CARREIRA, Denise. 0 direito à educação e à cultura em hospitais: caminhos e aprendizagens do Pequeno Príncipe. Curitiba: Associação Hospitalar de Proteção à Infância Dr. Raul Carneiro, 2016. p. 11-21. Disponível em: <http://pequenoprincipe.org.br/ projetosabermais/manual/Educ.pdf>. Acesso em: 29 de out. de 2017.

FREIRE, Paulo. Pedagogia da autonomia: saberes necessários à prática educativa. Rio de Janeiro: Paz e Terra. 1996.

FREIRE, Paulo. Pedagogia do oprimido. Rio de Janeiro: Paz e Terra. 2013, p. 108-152.

GENÚ, Marta. A linguagem, como ato social, em múltiplas expressões. In: GENÚ, Marta; DUARTE, Emerson (org.) Produção do conhecimento e experiências inovadoras na formação de professores de educação física. E-book. Belém: CCSE/UEPA, 2017a. p.147-150. Livro 1. Disponível em: <https://issuu.com/emersonmonte/docs/livro__ressignificar_2017>. Acesso em: 06 jun.2017.

GENÚ, Marta. Aportes sócio filosóficos, teorias do conhecimento e o corpoconsciente. In: GENÚ, Marta; DUARTE, Emerson (org.) Produção do conhecimento e experiências inovadoras na formação de professores de educação física. Belém: CCSE/UEPA, 2017b. p. 14-16. Livro 1. Disponível em: <https://issuu.com/emersonmonte/docs/livro__ressignificar_2017b $>$. Acesso em: 12 mar.2017.

GENÙ, Marta. Consciência corporal: uma concepção filosófico-pedagógica a apreensão do movimento. RBCE, Brasília, v. 22, n. 2, p. 115-131. jan. 2001. Disponível em: <http://revista.cbce.org.br/index.php/RBCE/article/view/416>. Acesso em: 17 de jun. de 2017c.

GENÚ SOARES, Marta. A abordagem da ação crítica e a epistemologia da práxis pedagógica. Educação \& Formação, PPGE/UECE, Fortaleza, v. 3, p. 55-70, 2018.

GENÚ, Marta. O corpoconsciente e a ação intencional para a formação humana. Revista Internacional D'humanitats, São Paulo/ Barcelona, v. 1, p. 17-24, 2019. 
GIL, Antonio Carlos. Métodos e técnicas de pesquisa social. São Paulo: Atlas, 2008.

LOPES, Elisângela H. Pedagogia hospitalar: a humanização na educação. 2010. Trabalho de conclusão de curso (Graduação em Pedagogia) - Instituto Superior de Educação da Faculdade Alfredo Nasser, Aparecida de Goiânia, 2010. Disponível em:

<http://www.unifan.edu.br/files/pesquisa/pedagogia\%2ohospitalar\%20a\%2ohumaniza\%c3\% a7\%c3\%a30\%20na\%20educa\%c3\%a7\%c3\%a30\%20-\%20elis\%c3\%82ngela\%2ohenrique.pdf >.

Acesso em: 29 out. 2017.

MARTINS, Ernesto Candeas. A corporeidade na aprendizagem escolar (entrelaços fenomenológicos do pensar e agir). Educar em Revistas, Curitiba, n. 56, p. 163-180, abr/jan. 2015. Disponível em: <http://www.scielo.br/pdf/er/n56/0101-4358-er-5600163.pdf>. Acesso em: 17 de jun. de 2017.

OLIVEIRA, T. C. de. Um breve histórico sobre as classes hospitalares no Brasil e no mundo. CONGRESSO NACIONAL DE EDUCAÇÃO - EDUCERE, 11. 2013, Curitiba. Anais [...]. Curitiba. 2013. p. 27686 -27697. Disponível em: <http://educere.bruc.com.br/ANAIS2013/ pdf/9052_5537.pdf>. Acesso em: 29 de out. 2017.

ROCHA, Marisa Lopes da; AGUIAR, Katia Faria de. Pesquisa-intervenção e a produção de novas análises. Psicol. Cienc. prof., Brasília, v. 23, n. 4, p. 64-73, 2003. Disponível em: <http://www.scielo.br/pdf/pcp/v23n4/v23n4a10.pdf>. Acesso em: 18 jun. 2017.

SILVA, Josianne, Maria Mattos da. O desenho na expressão dos sentimentos em crianças hospitalizadas. Fractal: Revista de Psicologia, Niterói, v. 22, n. 2, p. 447-456, maio/ago. 2010. Disponível em: http://www.periodicoshumanas.uff.br/Fractal/article/view/215/443. Acesso em: 13 out. 2017.

SILVA, Maria. Núcleo de educação popular Paulo Freire - NEP: lócus de formação permanente. In: OLIVEIRA, Ivanilde Apoluceno de (org.) Caderno de atividades pedagógicas em educação popular: relatos de pesquisas e de experiências dos grupos de estudos e trabalhos. 1. ed. Belém, EDUEPA, 2009. p. 34 -45.

Recebido em: 23/06/2018

Revisões requeridas: 04/02/2019

Aprovado em: 20/03/2019

Universidade do Estado de Santa Catarina - UDESC

Programa de Pós-Graduação em Educação - PPGE

Revista Linhas

Volume 20 - Número 44 - Ano 2019

revistalinhas@gmail.com 